\title{
RESPOSTA DE GENÓTIPOS DE ARROZ IRRIGADO AO ARRANJO DE PLANTAS ${ }^{1}$
}

\author{
SEVERO RODRIGUES RIEFFEL NETO², PAULO REGIS FERREIRA DA SILVA ${ }^{3}$, \\ VALMIR GAEDKE MENEZES ${ }^{4}$ e CARLOS HENRIQUE PAIM MARIOT ${ }^{5}$
}

\begin{abstract}
RESUMO - $\mathrm{O}$ aumento do rendimento de grãos do arroz irrigado pode ser buscado através da manipulação do arranjo de plantas. O objetivo desta pesquisa foi determinar a resposta de genótipos de arroz irrigado, com distintos tipos de planta e potenciais de rendimento, ao espaçamento entre linhas e à densidade de semeadura. Conduziram-se três experimentos no campo, no sistema de cultivo convencional, em Cachoeirinha, RS, nos anos agrícolas de 1994/95, 1997/98 e 1998/99. No primeiro ano, os tratamentos constituíram-se de três espaçamentos entre linhas $(12,5,20$ e $30 \mathrm{~cm})$, de três densidades de semeadura $(75,150$ e $225 \mathrm{~kg} / \mathrm{ha}$ ) e de duas cultivares (BR-IRGA 410 e IRGA 416). Nos outros dois experimentos, os tratamentos constaram de quatro espaçamentos entre linhas $(12,5,20,30$ e $40 \mathrm{~cm})$, três densidades de semeadura (30, 90 e $150 \mathrm{~kg} / \mathrm{ha}$ ), e de quatro genótipos de arroz irrigado (linhagem 959, híbrido XL-5 e as cultivares BR-IRGA 410 e IRGA 416). Nos três anos, a redução do espaçamento entre linhas aumentou o rendimento de grãos, independentemente do genótipo de arroz irrigado. Sob condições de cultivo com controle de plantas daninhas e de adequado manejo da irrigação, pode-se reduzir a densidade de semeadura.
\end{abstract}

Termos para indexação: Oryza sativa, densidade de semeadura, espaçamento, rendimento de grãos.

\section{RESPONSE OF LOWLAND RICE GENOTYPES TO PLANT ARRANGEMENT}

\begin{abstract}
Grain yield increase of lowland rice can be obtained through manipulation of plant arrangement. The objective of this research was to determine the response of grain yield of lowland rice genotypes with different types of plant and yield potentials to plant arrangement. Three experiments were conducted in the field, in Cachoeirinha, RS, Brazil, in the 1994/95, 1997/98 and 1998/99 growing seasons. In the first year, treatments consisted of three row spacings $(12.5,20$ and $30 \mathrm{~cm})$, three seed rates $(75,150$ and $225 \mathrm{~kg} / \mathrm{ha}$ ), and two rice varieties (BR-IRGA 410 and IRGA 416). In the other two experiments, treatments consisted of four row spacings $(12.5,20,30$ and $40 \mathrm{~cm})$, three seed rates $(30$, 90 and $150 \mathrm{~kg} / \mathrm{ha}$ ), and four rice varieties (959 line, XL-5 hybrid, BR-IRGA 410 and IRGA $416 \mathrm{com}-$ mercial cultivars). In all experiments, the reduction of row spacing increased grain yield, regardless of rice genotype. With efficient weed control and adequate water management, seed rate can be reduced.
\end{abstract}

Index terms: Oryza sativa, sowing rate, row spacing, yields, grain yield.

${ }^{1}$ Aceito para publicação em 8 de fevereiro de 2000.

Extraído da dissertação de mestrado apresentada pelo primeiro autor à Universidade Federal do Rio Grande do Sul (UFRGS).

${ }^{2}$ Eng. Agrôn., M.Sc., Dep. de Plantas de Lavoura, UFRGS, Caixa Postal 776, CEP 91540-000 Porto Alegre, RS.

E-mail: srieffel@bnet.co.br

${ }^{3}$ Eng. Agrôn., Ph.D., Prof. Adjunto, Dep. de Plantas de Lavoura, UFRGS. Bolsista do CNPq.

E-mail: paulo.silva@vortex.ufrgs.br

${ }^{4}$ Eng. Agrôn., M.Sc., Estação Experimental do Arroz, Instituto Riograndense do Arroz (IRGA), Caixa Postal 29, CEP 94930-000 Cachoeirinha, RS.

E-mail: irgafito@pro.via-rs.com.br

${ }^{5}$ Eng. Agrôn., mestrando, UFRGS.

E-mail: mariotch@bol.com.br

\section{INTRODUÇÃO}

O aumento do rendimento de grãos do arroz irrigado pode ser buscado através da adoção de práticas de manejo adequadas, de fácil utilização e de baixo custo para a lavoura. Elas devem incrementar o rendimento de grãos de arroz irrigado através da melhor utilização dos fatores do ambiente, sem elevar os custos de produção da lavoura. Entre estas práticas de manejo, insere-se o arranjo das plantas.

$\mathrm{Na}$ década de 80, vários trabalhos de pesquisa foram realizados com a cultura do arroz irrigado para determinar o arranjo das plantas mais adequado nas condições da lavoura no Rio Grande do Sul (Pedroso 
et al., 1980; Pedroso \& Reginatto, 1981; Pedroso, 1987). Segundo Pedroso (1987), a cultivar comercial BR-IRGA 409, sob espaçamento entre linhas de $30 \mathrm{~cm}$, produziu $10 \%$ mais grãos que no espaçamento entre linhas de $10 \mathrm{~cm}$, na média de três anos de cultivo. Esta vantagem do espaçamento entre linhas de $30 \mathrm{~cm}$ foi atribuída ao maior perfilhamento e número de panículas por $\mathrm{m}^{2}$. Mais recentemente, Andrade \& Amorim Neto (1995), em trabalho realizado no Rio de Janeiro com as cultivares de arroz irrigado INCA 4440 e a PESAGRO 104, não obtiveram diferença no rendimento de grãos entre os espaçamentos entre linhas de 20, 30 e $40 \mathrm{~cm}$. Porém, o número de perfilhos e o de panículas por $\mathrm{m}^{2}$ foram maiores no espaçamento entre linhas de $20 \mathrm{~cm}$.

Sob infestação de arroz vermelho, Menezes \& Silva (1998) obtiveram redução no rendimento de grãos quando associaram maior espaçamento entre linhas e menor densidade de semeadura, na média de dois genótipos de arroz irrigado (BR-IRGA 410 e IRGA 416).

Sem competição com plantas daninhas e utilizando genótipos de tipo tradicional e moderno de planta, Jones \& Snyder (1987) obtiveram 15\% de incremento no rendimento de grãos ao reduzir o espaçamento entre linhas de 25 para $15 \mathrm{~cm}$. Este aumento foi atribuído ao fato de o estádio reprodutivo ter coincidido com a época de maior radiação solar e com a ocorrência de temperaturas moderadas.

Outro aspecto do arranjo de plantas que pode ser manipulado é a densidade de semeadura. A escolha da densidade de semeadura depende da época de semeadura, tipo de solo, genótipo e do espaçamento entre linhas (Infeld \& Zonta, 1987; Pedroso, 1987). A densidade de semeadura preconizada pela pesquisa para o Rio Grande do Sul, nos sistemas de cultivo convencional e mínimo, situa-se em torno de 100 a $150 \mathrm{~kg} / \mathrm{h}$ a de sementes viáveis. O aumento da densidade de semeadura nem sempre resulta em elevação da densidade inicial de plantas. Isto foi evidenciado em experimento realizado por Pedroso (1987) com as densidades de semeadura de 100,150 e $200 \mathrm{~kg} / \mathrm{ha} \mathrm{em}$ que a população inicial situou-se em torno de 240 a 340 plantas por $\mathrm{m}^{2}$.

Em virtude do lançamento do genótipo de arroz IR 8, com tipo moderno de planta, houve modificação de várias características morfofisiológicas da planta. A introdução desta cultivar resultou em aumento do índice de colheita de 0,3 para 0,5 , e da produção de arroz, em 20\%, na América Latina (CuevasPerez et al., 1995). Para elevar ainda mais o potencial de rendimento, foi proposto um novo ideótipo de planta de arroz. Este modelo possui algumas características bioquímicas, fisiológicas e morfológicas que, quando combinadas, podem elevar em até $25 \%$ o potencial de rendimento (Dingluhn et al., 1991).

Juntamente com a proposta de mudança no ideótipo de planta, presentemente está se estudando a possibilidade de introduzir genótipos de arroz híbrido na lavoura do Rio Grande do Sul. Em estudos realizados em outras regiões do mundo, os híbridos apresentaram rendimento de grãos $20 \%$ a $30 \%$ superiores aos dos genótipos com tipo moderno de planta, em diferentes condições de manejo (Virmani \& Edwards, 1983).

O objetivo desta pesquisa foi determinar a resposta de genótipos de arroz irrigado, com distintos tipos de planta e potenciais de rendimento, ao espaçamento entre linhas e à densidade de semeadura.

\section{MATERIAL E MÉTODOS}

Três experimentos foram conduzidos no campo, na Estação Experimental do Arroz (EEA), do Instituto Riograndense do Arroz (IRGA), no município de Cachoeirinha, RS. O solo no local é classificado como planossolo e pertence à unidade de mapeamento Vacacaí (Embrapa, 1980). O clima da região é subtropical úmido, conforme classificação de Köppen (Brasil, 1973). Os procedimentos de preparo de solo e as demais práticas culturais adequadas seguiram as recomendações da pesquisa para a cultura do arroz irrigado no Sul do Brasil (EPAGRI, 1997). Nas três estações de crescimento, utilizou-se o sistema de cultivo convencional.

\section{Experimento 1}

Este experimento foi conduzido na estação de crescimento de 1994/95. Os tratamentos constaram de três espaçamentos entre linhas, três densidades de semeadura e de dois genótipos de arroz irrigado, os quais foram arranjados em blocos ao acaso, dispostos em parcelas subdivididas, com quatro repetições. Os espaçamentos entre linhas $(12,5,20$ e $30 \mathrm{~cm})$ foram locados nas parcelas principais. Nas subparcelas foram locadas as densidades de semeadu- 
ra $(75,150$ e $225 \mathrm{~kg} / \mathrm{ha})$, associadas aos genótipos de arroz irrigado (BR-IRGA 410 e IRGA 416). As cultivares comerciais utilizadas nos três experimentos possuem tipo moderno de planta e apresentam colmos fortes, folhas eretas e pilosas, porte baixo e grãos de classe longo fino. A cultivar BR-IRGA 410 possui ciclo de 125 dias, vigor inicial médio e alta capacidade de perfilhamento. A cultivar IRGA 416 possui ciclo de 110 dias e apresenta arquitetura de planta mais compacta que a da cultivar BR-IRGA 410 e menor estatura. O vigor inicial é considerado bom e a capacidade de perfilhamento média.

Todas as subparcelas apresentaram o mesmo comprimento $(7,2 \mathrm{~m})$; entretanto, as larguras foram diferenciadas segundo o espaçamento entre linhas. Nos espaçamentos entre linhas de 12,5 e $20 \mathrm{~cm}$ a largura foi de 2,4 m, compreendendo 19 e 12 linhas, respectivamente. Para o espaçamento entre linhas de $30 \mathrm{~cm}$, as subparcelas apresentaram $3 \mathrm{~m}$ de largura e dez linhas.

A semeadura foi realizada em 24 de novembro de 1994 , ajustando-se a densidade de semeadura pelo poder germinativo dos genótipos para $100 \%$ de sementes viáveis. A emergência das plântulas ocorreu no dia 1 de dezembro de 1994. A adubação de base com P e K foi aplicada por ocasião do preparo do solo, na dose de $100 \mathrm{~kg} / \mathrm{ha} \mathrm{de}$ cada nutriente. A fertilização nitrogenada foi de $150 \mathrm{~kg} / \mathrm{ha}$ de N, aplicada parceladamente: $20 \%$ aos 20 dias após a emergência das plântulas (DAE), 30\% no início do perfilhamento, e os $50 \%$ restantes no início do desenvolvimento da panícula (IDP). O controle de plantas daninhas foi feito aos $15 \mathrm{DAE}$, utilizando-se uma mistura dos herbicidas quinclorac $(350 \mathrm{~g} / \mathrm{ha})$ e pyrazosulfuron-ethyl (15 g/ha).

A densidade inicial das plantas por unidade de área foi avaliada aos $10 \mathrm{DAE}$, contando-se as plantas emergidas em duas subamostras de $1 \mathrm{~m}$ de linha. Os resultados foram expressos em número de plantas por $\mathrm{m}^{2}$. Para estimativa do rendimento de grãos, a área útil de cada unidade experimental foi a mesma, medindo $6 \mathrm{~m}$ de comprimento por $1,2 \mathrm{~m}$ de largura e contendo nove, seis e quatro linhas para os espaçamentos de $12,5,20$ e $30 \mathrm{~cm}$, respectivamente. Os resultados foram expressos em $\mathrm{kg} / \mathrm{ha}$, a $13 \%$ de umidade de grãos.

\section{Experimento 2}

O segundo experimento foi conduzido na estação de crescimento de 1997/98. Os tratamentos constituíram-se de quatro espaçamentos entre linhas, três densidades de semeadura e de quatro genótipos de arroz irrigado. O delineamento foi o de blocos ao acaso, dispostos em parcelas subdivididas, com quatro repetições. Os espaçamentos entre linhas $(12,5,20,30$ e $40 \mathrm{~cm})$ foram locados nas par- celas principais. Nas subparcelas foram locadas as densidades de semeadura (30, 90 e $150 \mathrm{~kg} / \mathrm{ha}$ de sementes) associadas aos quatro genótipos de arroz irrigado, sendo duas cultivares recomendadas, BR-IRGA 410 e IRGA 416, o híbrido XL-5, do programa de melhoramento da empresa Rice Tec. (híbrido), e a linhagem 959-1-2-2F-4-1-4-C, do programa de melhoramento do IRGA, que possui algumas características associadas ao novo tipo de planta (NTP). As características agronômicas dos dois últimos genótipos são as seguintes: o híbrido possui ciclo de 120 dias, produz 3 a 4 perfilhos férteis por planta, apresenta estatura de $82 \mathrm{~cm}$ e potencial de rendimento de 12,2 t/ha. Já a linhagem 959 apresenta ciclo precoce, colmos fortes e panículas densas.

Todas as subparcelas apresentaram o mesmo comprimento (5,7 m); entretanto, as larguras foram diferenciadas segundo o espaçamento entre linhas. Nos espaçamentos entre linhas de 20 e $40 \mathrm{~cm}$ a largura foi de $2,0 \mathrm{~m}$, compreendendo dez e cinco linhas, respectivamente. Nos espaçamentos entre linhas de 12,5 e $30 \mathrm{~cm}$, as subparcelas apresentaram, respectivamente, 1,25 e $1,80 \mathrm{~m}$ de largura, sendo compostas por dez e seis linhas.

A semeadura do arroz foi feita em 24 de novembro de 1997, ajustando-se a densidade de semeadura pelo poder germinativo dos genótipos para $100 \%$ de sementes viáveis. A emergência ocorreu em $1^{\circ}$ de dezembro de 1997 , em todos os genótipos.

A adubação de base foi realizada por ocasião do preparo do solo na dose de $100 \mathrm{~kg} / \mathrm{ha}$ de $\mathrm{P}_{2} \mathrm{O}_{5}$ e de $200 \mathrm{~kg} / \mathrm{ha}$ de $\mathrm{K}_{2} \mathrm{O}$. A fertilização nitrogenada, correspondente a $100 \mathrm{~kg} / \mathrm{ha}$ de $\mathrm{N}$, foi aplicada parceladamente: $30 \%$ aos 22 DAE, $35 \%$ aos 37 DAE e os $35 \%$ restantes aplicados no IDP de cada genótipo.

O controle de plantas daninhas foi realizado aos $5 \mathrm{DAE}$, utilizando-se uma mistura dos herbicidas quinclorac ( $350 \mathrm{~g} / \mathrm{ha})$ e pyrazosulfuron-ethyl ( $15 \mathrm{~g} / \mathrm{ha})$. Pela presença de "bicheira-da-raiz" (Oryzophagus oryzae Costa Lima, 1936), foi aplicado o inseticida carbofuran (10 kg/ha), aos 39 DAE. A irrigação definitiva da área experimental foi iniciada aos 7 DAE, mantendo-se a lâmina de água em torno de $10 \mathrm{~cm}$ de altura até a fase de grãos em estado pastoso.

A densidade inicial de plantas por unidade de área foi avaliada aos $16 \mathrm{DAE}$, contando-se as plantas emergidas em duas subamostras de $1 \mathrm{~m}$ de linha. Os resultados foram expressos em número de plantas por $\mathrm{m}^{2}$. $\mathrm{O}$ rendimento de grãos foi estimado pela colheita manual das panículas numa área útil de $5 \mathrm{~m}^{2}$ nos espaçamentos entre linhas de 20,30 e $40 \mathrm{~cm}$, compreendendo, respectivamente, seis, quatro e três linhas. No espaçamento entre linhas de $12,5 \mathrm{~cm}$, foi colhida a área útil de $3,75 \mathrm{~m}^{2}$, contendo seis linhas. Esta menor área útil no espaçamento entre linhas menor deveu-se ao fato de a semeadora de parcelas ter 10 
linhas, das quais foram deixadas duas linhas de cada lado como bordaduras. Os resultados foram expressos em $\mathrm{kg} / \mathrm{ha}$, a $13 \%$ de umidade de grãos.

\section{Experimento 3}

Este experimento foi realizado durante a estação de crescimento de 1998/99. As dimensões das subparcelas, o delineamento experimental e os tratamentos foram os mesmos utilizados no experimento 2 .

A semeadura do arroz foi feita em 23 de novembro de 1998, ajustando-se a densidade de semeadura pelo poder germinativo das sementes dos genótipos para $100 \%$ de sementes viáveis. A emergência ocorreu em 3 de dezembro de 1998, em todos os genótipos. Utilizou-se a mesma adubação de base do experimento 2 . A fertilização nitrogenada, correspondente a $120 \mathrm{~kg} / \mathrm{ha}$ de $\mathrm{N}$, foi aplicada parceladamente: $20 \%$ aos 27 DAE, $30 \%$ aos 39 DAE, e os $50 \%$ restantes, aplicados no IDP de cada genótipo.

A densidade inicial de plantas foi avaliada aos 7 DAE, a partir da contagem das plantas emergidas numa amostra de $0,5 \mathrm{~m}^{2}$ de três blocos que compunham o experimento. Os resultados foram expressos em número de plantas por $\mathrm{m}^{2}$.

O rendimento de grãos foi determinado através da colheita manual das panículas na área útil de $3,75 \mathrm{~m}^{2}$ no espaçamento entre linhas de $12,5 \mathrm{~cm}$, e na área útil de $5 \mathrm{~m}^{2}$, nos outros três espaçamentos entre linhas. Os resultados foram expressos em $\mathrm{kg} / \mathrm{ha}$, com umidade de grãos de $13 \%$. As demais práticas de manejo adotadas foram semelhantes às descritas no experimento 2 .

Os parâmetros avaliados, nas três estações de crescimento, foram analisados estatisticamente pelo teste F, $5 \%$ de probabilidade. Para os fatores de natureza quantitativa, realizou-se análise de regressão, testando-se os modelos linear e quadrático. A comparação entre médias foi realizada pelo teste Duncan, a $5 \%$ de probabilidade.

\section{RESULTADOS E DISCUSSÃO}

No experimento 1, a densidade inicial de plantas de arroz irrigado variou apenas em razão da densidade de semeadura. Ela aumentou à medida que se elevou a densidade de semeadura (Tabela 1). Quanto ao rendimento de grãos, houve apenas efeito simples do espaçamento entre linhas. A redução do espaçamento entre linhas de 30 para $12,5 \mathrm{~cm}$ e de $20 \mathrm{~cm}$ para $12,5 \mathrm{~cm}$ aumentou o rendimento de grãos em $15 \%$ e $8 \%$, respectivamente (Tabela 2 ).
No experimento 2, no parâmetro densidade inicial de plantas, houve interação entre espaçamento entre linhas e densidade de semeadura, e entre genótipos e densidade de semeadura. Independentemente da densidade de semeadura, o incremento no espaçamento entre linhas de 12,5 para $40 \mathrm{~cm}$ reduziu a densidade inicial de plantas, sendo a redução mais intensa na densidade de semeadura de $150 \mathrm{~kg} / \mathrm{ha}$ (Fig. 1). O incremento da densidade de semeadura aumentou a densidade inicial de plantas, nos quatro genótipos de arroz irrigado (Tabela 3).

Quanto ao rendimento de grãos, houve interação entre espaçamento entre linhas e genótipo, e entre densidade de semeadura e genótipo. $\mathrm{O}$ incremento no espaçamento entre linhas diminuiu o rendimento de grãos, de forma diferenciada, conforme os genótipos (Fig. 2). Nos genótipos IRGA 416, Híbrido e linhagem 959, a redução foi linear. Para cada

TABELA 1. Densidade de plantas de dois genótipos de arroz irrigado, 12 dias após a emergência, em três densidades de semeadura, na média de três espaçamentos entre linhas. EEA/IRGA, Cachoeirinha, RS, 1994/95'.

\begin{tabular}{cc}
\hline $\begin{array}{c}\text { Densidade de semeadura } \\
(\mathrm{kg} / \mathrm{ha})\end{array}$ & $\begin{array}{c}\text { Densidade inicial de } \\
\text { plantas }\left(\text { plantas } / \mathrm{m}^{2}\right)\end{array}$ \\
\hline 75 & $152 \mathrm{c}$ \\
150 & $272 \mathrm{~b}$ \\
225 & $333 \mathrm{a}$ \\
\hline
\end{tabular}

${ }^{1}$ Médias seguidas de mesma letra não diferem pelo teste de Duncan, a 5\% de probabilidade.

TABELA 2. Rendimento de grãos de arroz irrigado em três espaçamentos entre linhas, na média de três densidades de semeadura e de dois genótipos. EEA/IRGA, Cachoeirinha, RS, 1994/95'.

\begin{tabular}{cc}
\hline $\begin{array}{c}\text { Espaçamento entre linhas } \\
(\mathrm{cm})\end{array}$ & $\begin{array}{c}\text { Rendimento de grãos } \\
(\mathrm{kg} / \mathrm{ha})\end{array}$ \\
\hline 12,5 & $8.343 \mathrm{a}$ \\
20,0 & $7.662 \mathrm{~b}$ \\
30,0 & $7.078 \mathrm{c}$ \\
\hline
\end{tabular}

${ }^{1}$ Médias seguidas de mesma letra não diferem pelo teste de Duncan, a 5\% de probabilidade. 


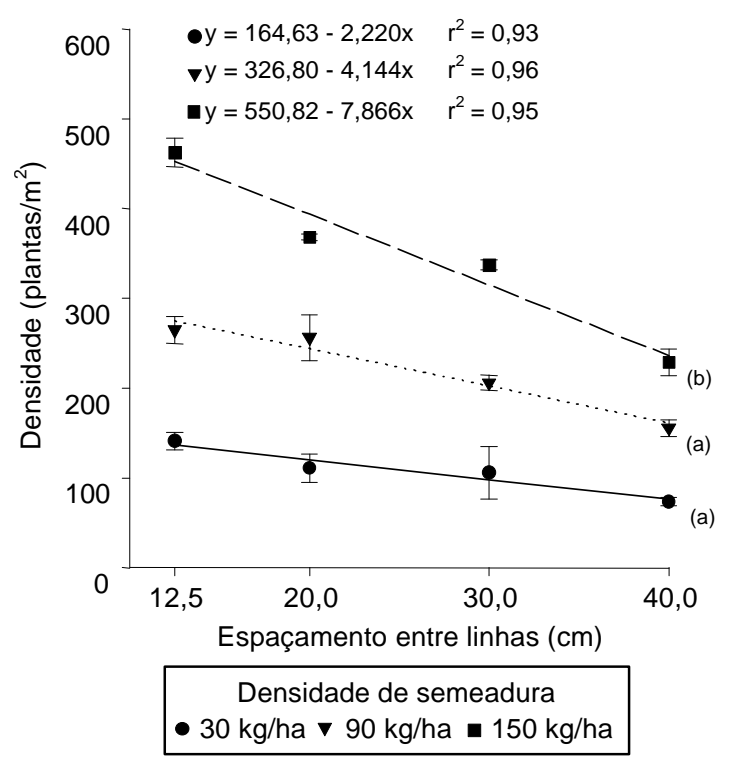

FIG. 1. Densidade inicial de plantas de arroz irrigado aos 20 dias após a emergência, em razão do espaçamento entre linhas, sob três densidades de semeadura, na média de quatro genótipos. As barras verticais representam o erro-padrão. Letras iguais após as retas indicam que não houve diferença significativa entre os coeficientes b das equações de regressão linear pelo teste $t$, a $5 \%$ de probabilidade. EEA/IRGA, Cachoeirinha, RS, 1997/98.

TABELA 3. Densidade inicial de plantas (plantas $/ \mathbf{m}^{2}$ ) de quatro genótipos de arroz irrigado, em três densidades de semeadura, na média de quatro espaçamentos entre linhas. EEA/IRGA, Cachoeirinha, RS, 1997/98.

\begin{tabular}{lccc}
\hline Genótipo & \multicolumn{3}{c}{ Densidade de semeadura (kg/ha) } \\
\cline { 2 - 4 } & 30 & 90 & 150 \\
\hline BR-IRGA 410 & $111 \mathrm{c}$ & $225 \mathrm{~b}$ & $345 \mathrm{a}$ \\
IRGA 416 & $127 \mathrm{c}$ & $248 \mathrm{~b}$ & $431 \mathrm{a}$ \\
Híbrido & $100 \mathrm{c}$ & $205 \mathrm{~b}$ & $316 \mathrm{a}$ \\
Linhagem 959 & $93 \mathrm{c}$ & $203 \mathrm{~b}$ & $305 \mathrm{a}$ \\
\hline${ }^{1}$ Médias seguidas de mesma letra, comparadas nas linhas, não diferem \\
pelo teste de Duncan, a 5\% de probabilidade.
\end{tabular}

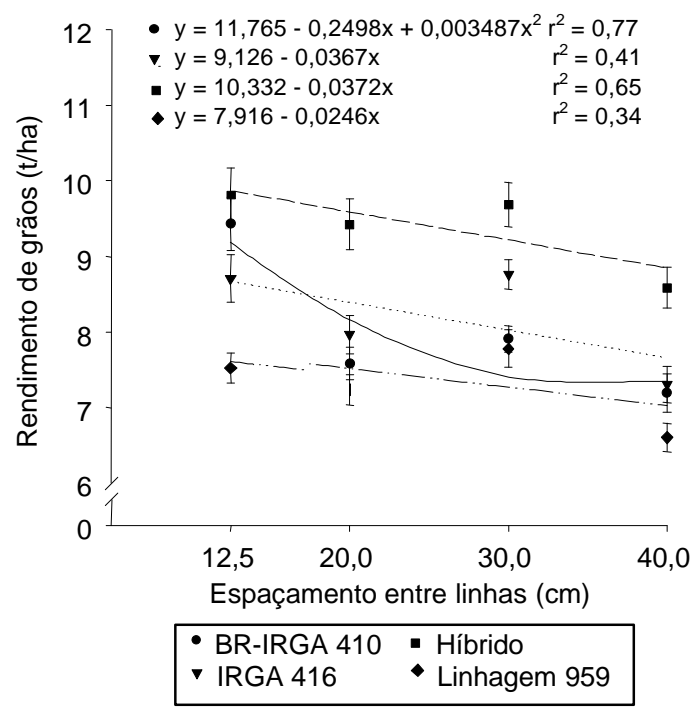

FIG. 2. Rendimento de grãos de quatro genótipos de arroz irrigado em razão do espaçamento entre linhas, na média de três densidades de semeadura. As barras verticais representam o erro padrão. EEA/IRGA, Cachoeirinha, RS, $1997 / 98$.

$10 \mathrm{~cm}$ de incremento no espaçamento entre linhas, o rendimento de grãos decresceu 367,372 e 246 kg/ha, respectivamente. Já no BR-IRGA 410, a resposta foi quadrática; o maior decréscimo do rendimento de grãos ocorreu quando se incrementou o espaçamento entre linhas de 12,5 para $20 \mathrm{~cm}$.

$\mathrm{O}$ incremento da densidade de semeadura de 30 para $150 \mathrm{~kg} / \mathrm{ha}$ aumentou em $9 \%$ e $12 \%$ o rendimento de grãos, respectivamente, nos genótipos BR-IRGA 410 e Híbrido (Tabela 4). O IRGA 416 obteve os maiores rendimentos de grãos nas densidades de semeadura de 30 e 90 kg/ha. Na linhagem 959, o incremento da densidade de semeadura não afetou o rendimento de grãos.

No experimento 3, houve efeito simples de densidade de semeadura na densidade inicial de plantas. $\mathrm{O}$ incremento da densidade de semeadura aumentou a densidade inicial de plantas (Tabela 5). Quanto ao rendimento de grãos, foram significativos os efeitos simples de espaçamento entre linhas, densidade de semeadura e de genótipo. O incremento do espaçamento entre linhas reduziu de forma quadrática 
TABELA 4. Rendimento de grãos (kg/ha) de quatro genótipos de arroz irrigado, em três densidades de semeadura, na média de quatro espaçamentos entre linhas. EEA/ IRGA, Cachoeirinha, RS, 1997/981.

\begin{tabular}{lccc}
\hline \multirow{2}{*}{ Genótipo } & \multicolumn{3}{c}{ Densidade de semeadura $(\mathrm{kg} / \mathrm{ha})$} \\
\cline { 2 - 4 } & 30 & 90 & 150 \\
\hline BR-IRGA 410 & $7.596 \mathrm{bB}$ & $8.182 \mathrm{bcAB}$ & $8.307 \mathrm{bA}$ \\
IRGA 416 & $8.416 \mathrm{aA}$ & $8.492 \mathrm{bA}$ & $7.649 \mathrm{cB}$ \\
Híbrido & $8.866 \mathrm{aB}$ & $9.382 \mathrm{aAB}$ & $9.889 \mathrm{aA}$ \\
Linhagem 959 & $7.104 \mathrm{bA}$ & $7.578 \mathrm{cA}$ & $7.179 \mathrm{cA}$ \\
\hline${ }^{1}$ Médias seguidas de mesma letra, minúscula na coluna e maiúscula na \\
linha, não diferem pelo teste de Duncan, a 5\% de probabilidade.
\end{tabular}

TABELA 5. Densidade de plantas sete dias após a emergência e rendimento de grãos de arroz irrigado, em três densidades de semeadura, na média de quatro espaçamentos entre linhas e de quatro genótipos. EEA/IRGA, Cachoeirinha, RS, 1998/991.

\begin{tabular}{ccc}
\hline $\begin{array}{c}\text { Densidade de } \\
\text { semeadura }(\mathrm{kg} / \mathrm{ha})\end{array}$ & $\begin{array}{c}\text { Densidade inicial de } \\
\text { plantas }\left(\text { plantas } / \mathrm{m}^{2}\right)\end{array}$ & $\begin{array}{c}\text { Rendimento de } \\
\text { grãos }(\mathrm{kg} / \mathrm{ha})\end{array}$ \\
\hline 30 & $118 \mathrm{c}$ & $7.483 \mathrm{a}$ \\
90 & $291 \mathrm{~b}$ & $7.667 \mathrm{a}$ \\
150 & $462 \mathrm{a}$ & $7.226 \mathrm{~b}$ \\
\hline
\end{tabular}

${ }^{1}$ Médias seguidas de mesma letra não diferem pelo teste de Duncan, a 5\% de probabilidade.

o rendimento de grãos (Fig. 3). Os maiores rendimento de grãos foram obtidos nas densidades de semeadura de 30 e 90 kg/ha (Tabela 5). O genótipo Híbrido obteve o maior rendimento de grãos e a linhagem 959 o menor (Tabela 6).

Nos três experimentos, o rendimento de grãos aumentou com a redução do espaçamento entre linhas, independentemente da densidade de semeadura. Esta resposta pode estar associada à menor competição intra-específica exercida entre plantas, principalmente por luz, nos espaçamentos entre linhas mais reduzidos pela distribuição mais uniforme de plantas na comunidade. Tais resultados estão de acordo com os obtidos por Menezes \& Silva (1998) com arroz irrigado, sob condições de competição com arroz vermelho. Eles observaram que a redução

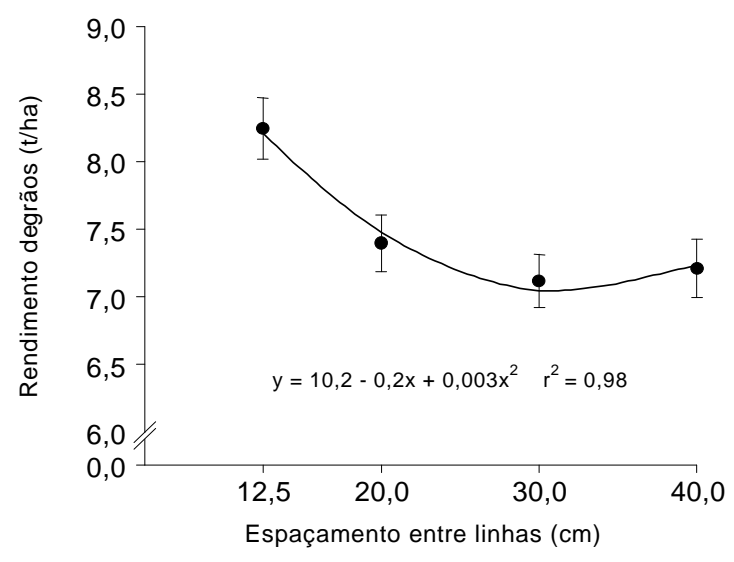

FIG. 3. Rendimento de grãos de arroz irrigado em razão do espaçamento entre linhas, na média de três densidades de semeadura e de quatro genótipos. EEA/IRGA, Cachoeirinha, RS, 1998/99.

TABELA 6. Rendimento de grãos de quatro genótipos de arroz irrigado, na média de quatro espaçamentos entre linhas e de três densidades de semeadura. EEA/IRGA, Cachoeirinha, RS, 1998/991.

\begin{tabular}{lc}
\hline Genótipo & Rendimento de grãos (kg/ha) \\
\hline BR-IRGA 410 & $7.667 \mathrm{~b}$ \\
IRGA 416 & $7.266 \mathrm{~b}$ \\
Híbrido & $8.872 \mathrm{a}$ \\
Linhagem 959 & $6.163 \mathrm{c}$ \\
\hline
\end{tabular}

${ }^{1}$ Médias seguidas de mesma letra não diferem pelo teste de Duncan, a 5\% de probabilidade.

do espaçamento entre linhas de 30 para $13,5 \mathrm{~cm}$, especialmente quando associada ao uso de densidades de semeadura mais elevadas ( 150 e $225 \mathrm{~kg} / \mathrm{ha}$ ), diminuiu a competição entre plantas de arroz, e, em consequiência, aumentou a capacidade de competição da cultura com o arroz vermelho. Outro aspecto, é o de que numa dada densidade de semeadura, o incremento no espaçamento entre linhas propicia maior acúmulo de sementes na linha. Especula-se que a maior deposição de sementes aumenta a competição entre plantas, podendo causar até a sua morte, em densidades de semeadura mais elevadas. Além disso, a duração do subperíodo semeadura-emergência também é afetada pela densidade de semeadura, temperatura e umidade do solo, profundidade de semeadura e pelas características da semente (Benja- 
min, 1990). A duração deste subperíodo altera o peso da plântula e, posteriormente, a sua capacidade de competição intra-específica. Segundo este autor, os efeitos sobre a duração deste subperíodo são mais pronunciados sob densidades de semeadura elevadas.

Outra hipótese que pode explicar o incremento verificado no rendimento de grãos no menor espaçamento entre linhas utilizado $(12,5 \mathrm{~cm})$, é o fato de as fases críticas da cultura terem coincidido com períodos de alta radiação solar e de moderada temperatura do ar (Jones \& Snyder, 1987). De acordo com esses autores, em anos de menor disponibilidade de radiação solar, as vantagens do espaçamento entre linhas menor (15 cm) não se manifestam. No experimento 1 (estação de crescimento 1994/95), não se evidenciou restrição na radiação solar e na temperatura do ar, durante o período do IDP até dez dias antes da maturação, obtendo-se valores neste período de $417 \mathrm{cal} / \mathrm{cm}^{2} /$ dia e de $18,3^{\circ} \mathrm{C}$. Estes valores de radiação solar e temperatura do ar estão acima dos limites mínimos preconizados por Souza (1990) que são de, respectivamente, $350 \mathrm{cal} / \mathrm{cm}^{2} /$ dia e $15^{\circ} \mathrm{C}$. No experimento 2, conduzido na estação de crescimento de 1997/98, as médias de radiação solar e de temperatura do ar no período crítico foram de, respectivamente, $376 \mathrm{cal} / \mathrm{cm}^{2} /$ dia e $18,8^{\circ} \mathrm{C}$. Analisandose estes dados de radiação solar percebe-se que, no período de $1^{\circ}$ a 10 de fevereiro de 1998 , a radiação solar média foi de $260 \mathrm{cal} / \mathrm{cm}^{2} /$ dia. No período de floração dos genótipos (11 a 15 de fevereiro de 1998), obteve-se média de temperatura do ar de $13,7^{\circ} \mathrm{C}$. Estas médias de radiação solar e de temperatura do ar podem ter reduzido o rendimento de grãos. No experimento 3, conduzido na estação de crescimento 1998/99, as médias de radiação solar e temperatura do ar foram de, respectivamente, $434 \mathrm{cal} / \mathrm{cm}^{2} /$ dia e $19^{\circ} \mathrm{C}$.

A resposta do rendimento de grãos à densidade de semeadura foi diferenciada nas três estações de crescimento. Tais resultados estão de acordo com os verificados por Counce (1987), que obteve respostas distintas com o aumento da densidade inicial de plantas, em função de ano, local de cultivo e de genótipo de arroz. No experimento 1 , não se verificou efeito de densidade de semeadura, na faixa de 75 a $225 \mathrm{~kg} / \mathrm{ha}$, no rendimento de grãos. No experimento 2 , o incremento da densidade de semeadura de 30 para $150 \mathrm{~kg} / \mathrm{ha}$ refletiu-se em maior rendimento de grãos nos genótipos Híbrido e BR-IRGA 410 (Tabela 4). Por outro lado, a densidade de semeadura de $150 \mathrm{~kg} / \mathrm{ha}$ reduziu o rendimento de grãos do genótipo IRGA 416, em relação às duas densidades menores. Este decréscimo do rendimento de grãos do IRGA 416 pode estar associado à excessiva densidade inicial de plantas (431 plantas por $\mathrm{m}^{2}$ ) verificada na maior densidade de semeadura (Tabela 4). Densidade inicial de plantas acima de 450 plantas por $\mathrm{m}^{2}$ pode reduzir o rendimento de grãos, por estar relacionada à ocorrência de estresses causados por doenças (Counce, 1987). O fato de a linhagem 959 não ter respondido à densidade de semeadura pode estar associado à sua maior capacidade de perfilhamento. A capacidade de perfilhamento de cada genótipo está associada à plasticidade de resposta ao espaçamento entre linhas e à densidade de semeadura, já que ela interfere na relação entre rendimento de grãos e população de plantas (Pereira, 1989; Wu et al., 1998). Segundo Wu et al. (1998), existe efeito competitivo e compensatório entre os perfilhos e seus componentes do rendimento, que promove a estabilidade do rendimento de grãos para um dado genótipo numa faixa de população de plantas.

No experimento 3, obteve-se maior rendimento de grãos nas densidades de semeadura de 30 e $90 \mathrm{~kg} / \mathrm{ha}$ em relação à de $150 \mathrm{~kg} / \mathrm{ha}$, independentemente do espaçamento entre linhas e de genótipo. Na maior densidade de semeadura (150 kg/ha), obteve-se emergência de 462 plantas por $\mathrm{m}^{2}$ (Tabela 5), fato que pode explicar a redução verificada no rendimento de grãos.

A redução do espaçamento entre linhas, associada à utilização de densidade de semeadura adequada, propicia fechamento mais rápido da entrelinha. Isto determina aumento da quantidade de radiação solar captada em decorrência da maior área foliar, possibilitando, com isto, maior produção de fotoassimilados e maior rendimento de grãos. Embora não quantificado neste experimento, observou-se que o menor espaçamento entre linhas, associado à densidade de semeadura mais elevada, propiciaram rápido fechamento das entrelinhas.

Em áreas experimentais onde as condições de cultivo propiciam emergência e estabelecimento de plântulas satisfatórios, e em que a adubação de base e nitrogenada e o controle de plantas daninhas são 
adequados, a redução da densidade de semeadura pode constituir-se em alternativa viável.

\section{CONCLUSÕES}

1. Os genótipos de arroz irrigado, independentemente do tipo de plantas e do potencial de rendimento, aumentam o rendimento de grãos com a redução do espaçamento entre linhas.

2. Quanto aos genótipos estudados, pode-se recomendar o uso de densidades de semeadura menores em relação às atualmente recomendadas, desde que haja condições de cultivo com adequado controle de plantas daninhas, correto manejo da irrigação e semente de boa qualidade.

\section{REFERÊNCIAS}

ANDRADE, W.E. de B.; AMORIM NETO, S. Densidade de semeadura e espaçamento entre linhas em cultivares de arroz irrigado no Estado do Rio de Janeiro. Lavoura Arrozeira, Porto Alegre, v.48, n.420, p.9$11,1995$.

BENJAMIN, L.R. Variation in time of seedling emergence within populations: a feature that determines individual growth and development. Advances in Agronomy, San Diego, v.44, p.1-25, 1990.

BRASIL. Ministério da Agricultura. Levantamento de reconhecimento de solo do Estado do Rio Grande do Sul. Recife : Divisão de Pesquisa Pedológica, 1973. 165p. (Boletim Técnico, 30).

COUNCE, P.A. Asymptotic and parabolic yield and linear nutrient content responses to rice population density. Agronomy Journal, Madison, v.79, n.5, p864-869, 1987.

CUEVAS-PEREZ, F.E.; BERRIO, L.E.; GONZALEZ, D.I.; CORREA-VICTORIA, F.; TULANDE, E. Genetic improvement in yield of semidwarf rice cultivars in Colombia. Crop Science, Madison, v.35, n.3, p.725-729, 1995.

DINGLUHN, M.; VRIES, F.W.T.P. de; DE DATTA, S.K.; LAAR, H.H. van. Concepts for a new plant type for direct seeded flooded tropical rice. In: INTERNATIONAL RICE RESEARCH INSTITUTE (Los Baños, Filipinas). Direct seeded flooded rice in the tropics. Manila, 1991. p.17-38.

EMBRAPA. Serviço Nacional de Levantamento e Conservação de Solos (Rio de Janeiro, RJ). Estudo expedito de solos do estado do Rio Grande do Sul e parte de Santa Catarina, para fins de classificação, correlação e legenda preliminar. Rio de Janeiro, 1980. 262p. (Boletim Técnico, 17).

EPAGRI. Estação Experimental de Itajaí. Arroz irrigado: recomendações técnicas da pesquisa para o Sul do Brasil. 4.ed.rev.atual. Itajaí : EPAGRI/EmbrapaCPACT/IRGA, 1997. 80p.

INFELD, J.A.; ZONTA, E.P. Densidade na BR-IRGA 411. In: REUNIÃO DA CULTURA DO ARROZ IRRIGADO, 14., 1987, Pelotas. Anais. Pelotas : Embrapa-CPATB/UFPel, 1987. p.168-172.

JONES, D.B.; SNYDER, G.H. Seeding rate and row spacing effects on yield and yield components of drill-seeded rice. Agronomy Journal, Madison, v.79, n.4, p.623626, 1987.

MENEZES, V.G.; SILVA, P.R.F. da. Manejo de arroz vermelho através do tipo e arranjo de plantas em arroz irrigado. Planta Daninha, Campinas, v.16, n.1, p.45$58,1998$.

PEDROSO, B. Densidade e espaçamento entre linhas para arroz (Oryza sativa L.) irrigado. Lavoura Arrozeira, Porto Alegre, v.40, n.370, p.6-60, 1987.

PEDROSO, B.; CABRAL, J.T.; GIORGI, I.U. Regional de densidades de semeadura para arroz irrigado. In: REUNIÃO DA CULTURA DO ARROZ IRRIGADO, 10., 1980, Porto Alegre. Anais. Porto Alegre : IRGA, 1980. p.93-95.

PEDROSO, B.; REGINATTO, M. da P.V. Densidade de semeadura em arroz irrigado. In: REUNIÃO DA CULTURA DO ARROZ IRRIGADO, 11., 1981, Pelotas. Anais. Pelotas : UEPAE-Pelotas, 1981. p.141-145.

PEREIRA, A.R. Competição intra-específica entre plantas cultivadas. O Agronômico, Campinas, v.41, n.1, p.5-11, 1989.

SOUZA, P.R. de. Alguns aspectos da influência do clima temperado sobre a cultura do arroz irrigado, no Sul do Brasil. Lavoura Arrozeira, Porto Alegre, v.43, n.389, p.9-11, 1990.

VIRMANI, S.S.; EDWARDS, I.B. Current status and future prospects for breeding hybrid rice and wheat. Annual Review of Plant Physiology, Palo Alto, v.36, p.145-214, 1983.

WU, G.; WILSON, L.; McCLUNG, A.M. Contribution of rice tillers to dry matter accumulation and yield. Crop Science, Madison, v.90, n.3, p.317-323, 1998. 